\title{
Mind Mapping untuk Pengembangan Perencanaan Karir
}

\author{
Jean Rala Bangkit ; Siti Fitriana ; Chr Argo Widiharto, \\ 1) Mahasiswa Bimbingan dan Konseling FIP UPGRIS Semarang \\ 2) Dosen Bimbingan dan Konseling FIP UPGRIS Semarang \\ 3) Dosen Bimbingan dan Konseling FIP UPGRIS Semarang
}

Program Studi Bimbingan dan Konseling

FIP - Universitas PGRI Semarang

\begin{abstract}
Abstrak
Penelitian ini bertujuan untuk mengetahui upaya layanan bimbingan kelompok dengan teknik mind mapping terhadap perencanaan karir siswa. Penelitian kuantitatif melalui metode peneltian True Experimental Design dengan model pre-test post-test control group design. Populasi dalam penelitian adalah siswa kelas X jurusan Multimedia SMK N 11 Semarang dengan jumlah 143 siswa. Kelas X Multimedia 3 adalah kelas yang dipergunakan untuk tryout sebanyak 35 siswa. Sampel dalam penelitian yaitu 16 siswa kelas X Multimedia 1 dan x Multimedia 4 SMK N 11 Semarang yang diambil dengan menggunakan teknik simple random sampling. Alat pengumpul data yang dipergunakan adalah skala perencanaan karir. Berdasarkan hasil analisis deskriptif menunjukkan ada peningkatan perencanaan karir pada kelompok eksperimen sebesar 78,875 point. Hasil perhitungan uji hipotesis menunjukkan thitung $=385,7>t_{\text {tabel }}=2,100$ dengan $\mathrm{db}=14 \mathrm{daraf}$

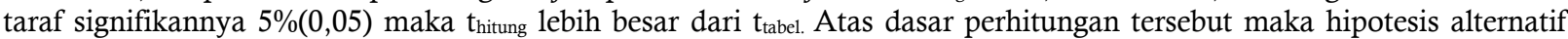
(Ha) yang berbunyi "ada pengaruh Layanan Bimbingan Kelompok Teknik Mind Mapping untuk Meningkatkan Perencanaan Karir Siswa kelas X Jurusan Multimedia SMK N 11 Semarang” diterima kebenarannya pada taraf signifikansi 5\%. Dengan demikian menunjukkan bahwa ada pengaruh layanan bimbingan kelompok dengan teknik mind mapping terhadap perencanaan karir siswa.
\end{abstract}

Kata kunci: Bimbingan Kelompok, Teknik Mind Mapping, Perencanaan Karir

\begin{abstract}
This study aims to determine the effort of group guidance services with mind mapping techniques on student career planning. Quantitative research through the True Experimental Design research method with the pre-test post-test control group design model. The population in this study was class X students majoring in Multimedia SMK N 11 Semarang with a total of 143 students. Class X Multimedia 3 is a class that is used for tryouts of 35 students. The samples in this study were 16 students of class X Multimedia 1 and x Multimedia 4 SMK N 11 Semarang taken using simple random sampling technique. The data collection tool used is the scale of career planning. Based on the results of descriptive analysis shows there is an increase in career planning in the experimental group by 78.875 points. The results of the calculation of the hypothesis test showed tcount $=385.7>t$ table $=2.100$ with $\mathrm{db}=14$ significance level of $5 \%(0.05)$ then tcount is greater than $\mathrm{t}$ table. On the basis of these calculations, the alternative hypothesis (Ha) which reads "there is an influence of Mind Mapping Technical Guidance Group Services to Improve Career Planning for Class X Students of Multimedia Department at SMK N 11 Semarang" is accepted at the significance level of 5\%. Thus it shows that there is an influence of group guidance services with mind mapping techniques on student career planning.

Keywords: Group Guidance, Mind Mapping Techniques, Career Planning
\end{abstract}




\section{PENDAHULUAN}

Masa remaja merupakan segmen kehidupan yang penting dalam siklus perkembangan siswa, dan merupakan masa transisi dari masa anak ke masa dewasa yang diarahkan kepada perkembangan masa dewasa yang sehat. Pada masa ini terjadi kegiatan kognitif tingkat, yaitu kemampuan merumuskan perencanaan dan pengambilan keputusan. Menurut Yusuf (dalam Atmaja 2009: 9-12). Kehidupan remaja saja tidak terlepas dari tugas-tugas perkembangan, Menurut Hurlock (2009 :21) mengemukakan bahwa tugas-tugas perkembangan merupakan social expectastions (harapan-harapan sosial masyarakat). Salah satu tugas perkembangan yang harus di penuhi oleh remaja adalah memilih dan mempersiapkan karir. Siswa pada jenjang pendidikan taraf Sekolah yang sedang berada dalam masa remaja dituntut untuk menjalani tugas-tugas perkembangan. Salah satu tugas perkembangan yaitu mencapai kematangan dalam pilihan karir masa depan.

Selain itu persaingan dunia kerja di era globalisasi saat ini semakin ketat ditambah dengan adanya MEA (Masyarakat Ekonomi ASEAN) yang sudah diberlakukan di Indonesia. Banyaknya tenaga asing yang bebas keluar masuk ke Indonesia membuat tenaga kerja Indonesia tergeser karena persaingan. Hal ini menambah buruknya kondisi ketenagakerjaan di Indonesia. Dengan demikian, diperlukan bekal keterampilan dan potensi khusus untuk bersaing dengan tenaga kerja asing dan meningkatkan jumlah lapangan kerja. Dengan Situasi ini menyebabkan meningkatnya jumlah pengangguran di Indonesia. Pada dasarnya manusia ingin memiliki suatu pekerjaan yang tepat dan sukses dalam pekerjaan karena manusia membutuhkan pekerjaan untuk memperoleh hasil yang baik atas pekerjaan. Karir seseorang bukanlah hanya sekedar apa yang telah di jabatkan, melainkan suatu pekerjaan atau jabatan yang benar-benar sesuai dengan keinginan dan kemampuan yang dimilikinya, sehingga seseorang akan menikmati pekerjaan (Inriana, 2015).

Menurut Adiputra (2015: 45) Pekerjaan yang ditekuni seseorang tidak serta merta merupakan karir, kata pekerjaan lebih mengacu pada setiap proses atau kegiatan untuk mengahasilkan barang dan jasa, sedangkan kata karir lebih mengarah pada suatu jabatan atau pekerjaan sendiri tidak serta merta merupakan karir. Kata pekerjaan (work,job,employment) menunjukan pada setiap kegiatan yang mengasilkan barang atau jasa, sedangkan kata karir (career) lebih menunujukan pada pekerjaan atau jabatan yang ditekuni dan diyakini sebagai panggilan hidup, yang meresapi seluruh alam pikiran dan perasaan seseorang, serta mewarnai seluruh gaya hidupnya. Oleh karena itu, pemilihan karir lebih memerlukan persiapan dan perencanaan yang matang dari sekedar mendapat pekerjaan yang sifatnya sementara waktu.

Karir adalah bagian hidup yang berpengaruh pada kebahagian hidup manusia secara keseluruhan. Definisi karir menurut Meldona dan Siswanto (2011: 256) yaitu semua pekerjaan yang dilakukan seseorang selama masa kerjanya yang memberikan kelangsungan, keteraturan dan nilai bagi kehidupannya. Konsep karir yang luas dan kompleks menimbulkan makna yang berbeda-beda. Makna yang popular tercermin dalam gagasan peningkatan garis kerja adalah memperoleh penghasilan yang lebih besar. Memiliki tanggung jawab yang lebih besar dan memperoleh status, kekuasaan yang lebih besar. Namun demikian, karir merupakan sejumlah konstruk konsep, dengan beberapa persamaan. Karir merupakan istilah yang sudah lazim dalam bahasa sehari-hari yang digunakan dalam pengertian, antara lain sejarah pekerjaan seseorang, rangkaian dan pola dalam kedudukan dan posisi pekerjaan, dan kemajuan dalam pekerjaan atau biasanya dalam hidup menurut Kaswan (2014: 11).

Menurut Yusuf dkk, (2011:30) seseorang dikatakan mempunyai perencanaan karir yang baik apabila mempunyai ciri - ciri sebagai berikut : (1) mengetahui cara memilih program studi agar tujuan dan arus karir akan menjadi dan terarah, sehingga dalam pencapaian sebuah karir akan lebih maksimal, (2) mempunyai motivasi untuk mencari informasi tentang adanya informasi akan membantu individu dalam melihat gambaran pekerjaan yang ideal, (3) dapat memilih pekerjaan yang baik sesuai dengan bakat, minat dan kemampuan agar individu mampu merencanakan langkah - langkah yang harus dilakukan untuk mencapai pencapaian karir tersebut dan membuat penalaran yang rasional sebelum mengambil keputusan mengenai karir yang diinginkan, (4) mampu memilih pekerjaan yang tepat atau memilih perguruan tinggi setelah lulus sekolah dengan perencanaan yang matang untuk melihat jauh kedepan guna mencapai sukses karir.

Karir seseorang tidak hanya mencakup pekerjaan apa yang dijalani, melainkan juga mempertimbangan dengan keselaraan dan kesesuaian dalam potensi-potensi yang ada dirinya. ketika seseorang sesuai dengan 
harapannya akan merasa puas dengan pekerjaan yang dimilikinya dan akan berusaha meningkatkan kinerja dan prestasinya semaksimal mungkin. Menurut Mahdalena,dkk (2013:2) menjelaskan bahwa kehidupan nyata, sering terjadi berbagai permasalahan karir yang dihadapi para siswa yang tidak dapat diatasi oleh diri nya sendiri sehingga siswa membutuhkan bantuan dari pihak lain. Permasalahan karir yang terjadi pada remaja biasanya berkaitan dengan bingung untuk memilih di masa depan, perencanaan karir masa depan, pengambilan keputusan tentang karir di masa depan. Dan informasi tentang kelompok kerja yang ada dengan persyaratan yang harus dimiliki.

Berdasarkan fenomena lain yang dikemukanan oleh Badan Pusat Statistik (BPS) Tahun 2018 mencatat pengangguran tertinggi merupakan lulusan pendidikan Sekolah Kejurusan (SMK) dan Diploma. Dilihat dari tingkat pendidikannya,Tingkat Pengangguran Terbuka (TPT) Jawa Tengah Agustus 2018 jumlah penggangguran meningkat 0,81 juta orang 4,51 persen. Data BPS menjabarkan bahwa tingkat pengangguran terbuka (TPT) didominasi penduduk berpendidikan Sekolah Menengah Kejuruan (SMK) tertinggi diantara tingkat pendidikan yaitu sebesar 10,85 persen, disusul jenjang Sekolah Menengah Atas (SMA) 6,62 persen, DiplomaI/II/III sebesar 8,33 persen, dilanjutkan Universitas 6,93 persen. Angka pengangguran untuk jenjang SMK lebih tinggi. Hal ini disebabkan kurangnya lapangan pekerjaan yang dibutuhkan. Kondisi tersebut karena belum memenuhi harapan, kurangnya mampu menyeseuaikan diri dengan perkembangan ilmu dan teknologi tetapi juga kurang mampu mengembangkan diri dari karirnya di tempat kerja.

Dengan demikian penelitian yang dilakukan oleh Amin Budiman (2012) melaporkan bahwa; 90\% siswa SMA di kabupaten Bandung menyatakan bingung dalam memilih karir untuk masa depan. Pada kenyataan, siswa SMA juga belum bisa mencapai tugas perkebangan karir. Siswa SMA masih ragu dan tidak memiliki kesiapan membuat keputusan karir yang tepat bagi masa depan. Fakta ini menyatakan bahwa banyak remaja mengalami kebimbangan. Ketidaksiapan dan stress dalam pembuatan keputusan karir kurang peduli terhadap karir, serta pemilihan atas dasar mengikuti teman. Terkait permasalahan tersebut perencanaan karir sangatlah penting merupakan suatu hal yang hendaknya dilakukan oleh siswa sedini mungkin. Setidaknya siswa memiliki gambaran dan rencana yang tertata dengan baik untuk masa depan sesuai yang diinginkan dan sesuai dengan kemampuan yang ada di dalam dirinya.

Kenyataan di lapangan tersebut sesuai dengan kondisi siswa kelas X jurusan Multimedia di SMK N 11 Semarang, berdasarkan hasil observasi dan wawancara yang dilakukan pada tanggal 11 april 2019 kepada guru BK yang menyatakan bahwa siswa kelas X di SMK N 11 Semarang jurusan Multimedia tempat peneliti melakukan penelitian diketahui bahwa sebagian siswa sudah memiliki impian untuk masa depannya dalam hal karir seperti profesi apa yang ingin mereka pilih, namun mereka masih bingung harus berbuat apa seperti, permasalahan perencanaan karir siswa yaitu : (1) siswa belum mampu memahami tentang dirinya mengenai kelebihan dan kekurangan yang dimiliki, (2) siswa masih bingung menentukan arah tujuan ke depannya setelah lulus sekolah, (3) kurang informasi tentang pemahaman karir atau pekerjaan yang sesuai dengan kemampuan siswa yang dimiliki, (4) kurangnya dukungan dan arahan dari orang tua, (5) kurangnya pemahaman siswa tentang berbagai jenis karir / pekerjaan yang memiliki prospek kerja yang baik di masa depan. Hasil Angket Kebutuhan Peserta Didik (AKPD) yang sudah disebar pada tanggal 11 maret 2019 diperoleh hasil bahwa siswa SMK N 11 Semarang jurusan Multimedia terindikasi memiliki Perencanaan karir yang rendah.

Untuk menghadapi kondisi tersebut, dibutuhkan Perubahan dan perkembangan dunia pekerja tersebut, adapun perubahan paradigma baru yang didasari pada protean career, Menurut Hall dan Moss mengemukakan bahwa protean career merupakan karir yang dijalankan oleh seseorang, perubahan dari waktu ke waktu, sebagai perubahan lingkungan individu sesuai bakat, minat dan kemampuan individu. Melihat fenomena yang terjadi pada siswa-siswi tersebut, untuk meingkatkan kemampuan perencanaan karir siswa digunakan beberapa cara yang efektif, salah satunya melalui teknik yang sesuai untuk menyelesaikan masalah perencanaan karir adalah dengan teknik Mind Mapp Menurut Buzan (2006: 4-5) Mind Mapp adalah cara mencatat yang kreatif, efektif, dan secara harfiah akan "memetakan" Pikiran-pikiran kita Mind Mapp sangat sederhana. Menurut Michael Michalko The Ultimate Book Of Mind Mapping ini akan membantu kita menemukan banyak contoh praktis cara penggunaan Mind Mapping membantu merencanakan dan mengatur hidup demi keberhasilan maksimal, memunculkan ide-ide baru yang kreatif dan mengagumkan, dan menyerap fakta serta informasi baru dengan sangat mudah. 
Bimbingan dan Konseling yang membantu siswa SMK dalam hal karir disebut dengan bimbingan karir. Melalui bimbingan karir diharapkan siswa mampu mengambil keputusan serta merencanakan karir yang tepat dan sesuai dengan keadaan dirinya, Bimbingan karir dapat diberikan melalui berbagai cara dan bentuk layanan salah satunya yaitu dengan layanan bimbingan kelompok. Bimbingan kelompok adalah proses pemberi bantuan yang diberikan individu dalam situasi kelompok yang ditujukan untuk mengembangkan potensi siswa. Bahkan ada diantara siswa yang menyerahkan pilihan karirnya pada teman sebaya atau keluarganya menurut Romlah (2001: 3). Dengan demikian penentuan karir yang tepat dan sesuai dengan kemampuan maupun potensi yang dimiliki oleh siswa perlu direncanakan terlebih dahulu.

Dari alasan itulah untuk meningkatkan perencanaan karir dengan menggunakan layanan bimbingan kelompok yang diberikan kepada peserta didik dapat merangsang perkembangan kemajuan berfikir siswa untuk menyelesaikan rendahnya perencanaan karir yang dihadapi oleh siswa dengan tepat. Serta dapat memiliki gambaran tentang pendidikan sekolah yang lebih relevan dengan kehidupan khususnya untuk dunia kerj, dengan begitu layanan Bimbingan kelompok dengan teknik Mind Mapping sangat tepat untuk perencanaan karir siswa agar menyerap informasi dan diingatnya kembali.

Tujuan penelitian yaitu untuk mengetahui Pengembangan Perencanaan Karir melalui Layanan Bimbingan Kelompok dengan Teknik Mind Mapping Siswa kelas X Multimedia SMK Negeri 11 Semarang.

\section{METODE}

Penelitian ini menggunakan metode true experiment design dengan model pretest-postest control group design, dengan adanya pretest dan Postest untuk mengetahui keadaan awal dan akhir kelompok eksperimen dan kelompok kontrol (Sugiyono, 2014). Penelitian ini dilaksanakan di SMK N 11 Semarang ditemukan permasalahan perencanaan karir siswa. Pada siswa kelas X jurusan multimedia penelitian dilaksanakan pada tanggal 19 Agustus - 30 September 2019 pada sampel yang diambil secara random pada kelas X jurusan multimedia dengan rincian menyusun proposal penelitian, penyusunan instrumen, uji keterbacaan instrument, penyusunan hasil penelitian, dan penyempurnaan.

Populasi dalam penelitian ini adalah kelas X jurusan Multimedia SMKN N 11 Semarang. Dalam penelitian ini pengambilan sampel dilakukan dengan teknik cluster random sampling, yaitu pengambilan dilakukan secara random di dapatkan daerah/kelas X multimedia 4, dan di dapatkan sampel 16 siswa, dengan 8 siswa kelas $\mathrm{X}$ multimedia 1 dan 8 siswa kelas X multimedia 4 .

Teknik pengumpulan data yang digunakan dalam penelitian ini skala perencanaan karir digunakan untuk membandingkan skor sebelum mendapatkan perlakuan dengan setelah mendapatkan perlakuan mengalami peningkatan atau tidak. Instrumen yang digunakan adalah sebuah skala psikologis, hasil uji coba di analisis untuk mengetahui validitas dan realiabilitas. Dari 36 item pernyataan terdapat 25 item pernyataan yang valid.

Analisis data yang dilakukan pada penelitian ini terdiri pre-test dan data post-test kemudian analisis deskriptif evaluasi hasil proses dan hasil, analisis deskriptif data pre-test dan data post-test sebelum diberi perlakuan dan sesudah diberikan perlakuan menggunakan layanan bimbingan kelompok dengan teknik Mind mapping sudah dinormalitaskan dengan menggunakan uji lilifors dan sudah dihomogenkan menggunakan uji F. kemudian untuk mengetahui pengaruh layanan bimbingan kelompok dengan teknik mind mapping digunakan hipotesis Uji $t$ dan Uji-t.

\section{HASIL}

Perhitungan uji normalita pada penelitian ini menggunakan uji lilifors dengan taraf signifikan $5 \%$. Kriteria dalam uji normalitas ini adalah jika Lo $<\mathrm{L}_{\text {tabel. }}$ Maka data berdistribusi normal, sedangkan jika Lo $>\mathrm{L}_{\text {tabel }}$ maka data berdistribusi tidak normal dan perhitungan homogenitas pada penelitian ini menggunakan uji $\mathrm{F}$. Rekapitulasi hasil perhitungan normalitas data pre-test sampel berikut: 
Tabel 1. Uji Normalitas Data Pre-test Perencanaan Karir

\begin{tabular}{|c|c|c|c|}
\hline Kelompok & $\mathrm{L}_{0}$ & $\mathrm{~L}_{\text {tabel }}$ & Kesimpulan \\
\hline Eksperimen & 0,21204 & 0,285 & Berdistribusi Normal \\
\hline Kontrol & 0,1520 & 0,285 & Berdistribus Normal \\
\hline
\end{tabular}

Berdasarkan tabel terlihat hasil perhitungan yang diperoleh dari nilai pre-test, maka berdasarkan diperoleh Lo $<\mathrm{L}_{\text {tabel }}$ yaitu $0,21204<0,285$ pada kelompok eksprimen dan 0,1520<0,285 pada kelompok kontrol pada taraf signifikans 5\% dengan N 8, maka Ho diterima, sehingga dapat disimpulkan bahwa data pre-test perencanaan karir berdistribusi normal.

Tabel 2. Uji Homogenitas Data Pre-test Perencanaan Karir

\begin{tabular}{|c|c|c|}
\hline $\mathrm{X}_{\text {hitung }}$ & $\mathrm{X}_{\text {tabel }}$ & Kesimpulan \\
\hline 1,527 & 2,85 & Kedua Kelompok Homogen \\
\hline
\end{tabular}

Berdasarkan uji homogenitas data pre-test pada tabel 2 karena F Hitung $<$ Ftabel yaitu 1,527 $<2,85$ maka Ho diterima. Sehingga dapat disimpulkan bahwa sampel berasal dari populasi yang sama atau homogen.

Perhitungan uji normalitas pada penelitian ini menggunakan uji lilifors dengan taraf signifikan $5 \%$. Kriteria uji normalitas ini adalah jika Lo $<\mathrm{L}_{\text {tabel }}$ maka data berdistribusi normal dan perhitungan homogenitas pada penelitian ini menggunakan pada penelitian ini menggunakan uji F. Rekapitulasi hasil perhitungan normalitas dan homogenitas data post-test sampe berikut:

\section{Tabel 3. Uji Normalitas Data Post-test Perencanaan Karir}

\begin{tabular}{|c|c|c|c|}
\hline Kelompok & $\mathrm{L}_{0}$ & $\mathrm{~L}_{\text {tabel }}$ & Kesimpulan \\
\hline Eksperimen & 0.10189 & 0,285 & Berdistribusi Normal \\
\hline Kontrol & 0.27146 & 0,285 & Berdistribus Normal \\
\hline
\end{tabular}

Berdasarkan tabel terlihat hasil perhitungan yang diperoleh dari nilai post-test, maka berdasarkan diperoleh $\mathrm{Lo}<\mathrm{L}_{\text {tabel }}$ yaitu $0.10189<0,285$ pada kelompok eksperimen dan $0.27146<0,285$ pada kelompok kontrol pada taraf signifikans 5\% dengan N 8, maka Ho diterima, sehingga dapat disimpulkan bahwa data post-test perencanaan karir berdistribusi normal.

Tabel 4 Uji Homogenitas Data Post-test Perencanaan Karir

\begin{tabular}{|c|c|c|}
\hline $\mathrm{X}_{\text {hitung }}$ & $\mathrm{X}_{\text {tabel }}$ & Kesimpulan \\
\hline 1,215 & 2,85 & Kedua Kelompok Homogen \\
\hline
\end{tabular}

Berdasarkan uji homogenitas data post-test pada tabel 4 karena F Hitung < Ftabel yaitu 1,215 $<2,85$ maka Ho diterima. Dapat disimpulkan bahwa sampel berasal dari populasi yang sama atau homogen.

Gambar 1. Perbandingan Hasil data Pre-test dan Hasil Data Post-test Kelompok Ekseprimen

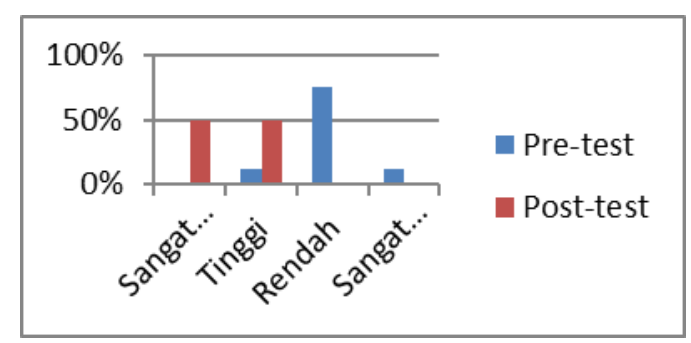

Berdasarkan perbandingan hasil data pre-test dan hasil data post-test kelompok eskperimen pada tabel gambar 1 sebelum diberikan treatment dan setelah diberikan treatment menggunakan layanan bimbingan kelompok dengan teknik mind mapiing dari hasil skala perencanaan karir siswa kelas X jurusan Multimedia 
SMK N 11 Semarang dapat diketahui bahwa terlihat ada perubahan perencanaan karir pada kelompok eksperimen setelah diberikan treatment menggunakan layanan bimbingan kelompok dengan teknik mind mapingg yaitu terjadi perubahan tingkatan kategori rendah menjadi tinggi, pada kelompok eksperimen hasil data pre-test dan post-test memperoleh skor meningkat dari skor nilai tertinggi 63 dan skor nilai terendah 36 menjadi skor nilai tertinggi 90 dan skor nilai terendah 64, rata-rata hasil data pre-test dan post-test memperoleh skor meningkat dari 52,75 menjadi 78,875 dengan demikian terjadi peningkatan nilai tertinggi dan terendah sebesar 27 dan terjadi peningkatan nilai rata-rata sebesar 26,125 point.

Berikut ini adalah materi yang digunakan dalam treatment yaitu layanan bimbingan kelompok dengan teknik mind mapping diri sswa kelas X jurusan multimedia SMK N 11 Semarang. Mind maaping yang digunakan dalam treatment berupa mind mapping yang dirangkai menjadi alur-alur materi demi materi. Berikut bisa dilihat pada tabel 5:

Tabel 5 Materi Trearment

\begin{tabular}{|c|l|}
\hline NO & \multicolumn{1}{|c|}{ MATERI } \\
\hline 1 & Pemahaman diri bakat dan minat \\
\hline 2 & Informasi Karir \\
\hline 3 & Membuat keputusan yang realistis \\
\hline 4 & Kemampuan merencanakan dimasa depan \\
\hline 5 & Sifat positif dalam dunia kerja \\
\hline
\end{tabular}

\section{Data Evaluasi Proses}

\section{Gambar 2. Hasil Evaluasi Proses}

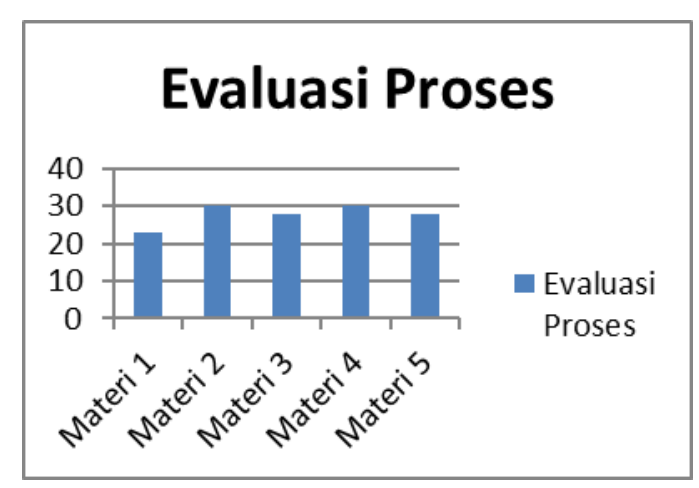

Berdasarkan treatment yang telah dilakukan yaitu pemberian layanan bimbingan kelompok dengan teknik mind maaping, maka dapat diperoleh data evaluasi proses layanan bimbingan kelompok mulai dari pertemuan pertama sampai dengan pertemuan ke lima dari 8 siswa kelompok eksperimen kelas $\mathrm{X}$ jurusan Multimedia SMK N 11 Semarang diperoleh data hasil evaluasi proses menunjukkan terjadinya peningkatan dari pertemuan pertama sampai pertemuan ke lima dengan skor 23,30,28,30,28. Kategori baik berubah menjadi sangat baik. 


\section{Data Evaluasi Hasil}

Gambar 3. Hasil Evaluasi Hasil

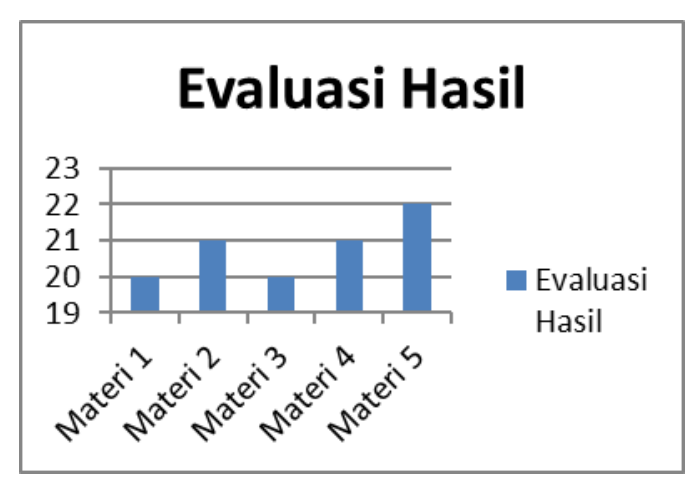

Berdasarkan treatment yang telah dilakukan yaitu pemberian layanan bimbingan kelompok dengan teknik mind mapping, maka dapat diperoleh data evaluasi hasil layanan bimbingan kelompok mulai dari pertemuan pertama sampai dengan pertemuan kelima dari 8 siswa kelompok eksperimen kelas X jurusan Multimedia SMK N 11 Semarang diperoleh dari hasil evaluasi hasil menunjukkan terjadinya peningkatan dari pertemuan pertama sampai pertemuan kelima yaitu dengan skor nilai 20,21,20,21,22. Dari kategori baik menjadi sangat baik.

Uji hipotesis peneliti menggunakan yaitu Uji dengan teknik analisis $t$ tes untuk menguji nilai pre-test diperoleh hasil $t_{\text {hitung }} 0,64<\mathrm{t}_{\text {tabel }} 2,144$. Dapat disimpulkan bahwa tidak ada perbedaan perencanaan karir siswa antara kelompok eksperimen dan kelompok kontrol.

Hipotesisi kedua yaitu uji-t tets yang bertujuan untuk mengetahui seberapa besar pengaruh antara ratarata pre-test dan rata post-test. Dari hasil perhitungan uji t-test diperoleh hasil $t_{\text {hitung }} 385,7>t_{\text {tabel }}, 2,100$ maka Ho ditolak dan Ha diterima jadi dapat disimpulkan bahwa ada pengaruh layanan bimbingan kelompok dengan teknik mind mapiing terhadap perencanaan karir siswa kelas X jurusan Multimedia SMK N 11 Semarang karena memiliki perbedaan yang signifikan dilihat dari perhitungan uji t.

\section{SIMPULAN}

Berdasarkan hasil analisis deskriptif yang telah dilakukan dalam penelitian ini terlihat tingkat perubahan hasil data pre-test dan post-test dari kategori rendah menjadi tinggi kemudian hasil data evaluasi proses dan evaluasi hasil yang menunjukkan tingkat perubahan dari kategori baik hingga menjadi sangat baik. Dimana hasil uji hipotesis yang telah dilakukan dalam penelitian ini diketahui bahwa hasil $t_{\text {hitung }}$ sebesar 385,7 dan $t_{\text {tabel }}$, sebesar 2,100. Hal tersebut menunjukkan bahwa $t_{\text {hitung }} 385,7>t_{\text {tabel }}, 2,100$ maka Ha diterima dan Ho ditolak. Berdasarkan hal tersebut dapat disimpulkan bahwa hipotesis alternative (Ha) yang berbunyi "ada pengaruh layanan bimbingan kelompok dengan teknik mind mapping terhadap perencanaan karir siswa kelas X jurusan multimedia SMK N 11 Semarang" diterima kebenarannya. Dengan demikian menunjukkan bahwa layanan bimbingan kelompok dengan teknik mind mapping dapat meningkatkan perencanaan karir siswa.

\section{SARAN}

Saran-saran yang dapat peneliti sampaikan dalam penelitian ini sebagai berikut: 1) Guru BK dapat menerapkan bimbingan karir untuk meningkatkan perencanaan karir siswa, 2) Peneliti lanjutan dapat mengembangkan penelitian ini dengan melakukan inovasi layanan bimbingan dan konseling untuk meningkatkan perencanaan karir siswa. 


\section{DAFTAR PUSTAKA}

Adiputra, Sofwan. 2015. "Penggunaan teknik Modeling Terhadap Perencanaan Karir". Jurnal Fokus Konseling.Volume 1. Nomor 1. Hal 45-56. (diakses Januari 2015). STKIP Muhammadiyah Pringsewu.

Atmaja, Tri Tandar.2014. "Upaya meningkatkan Perencanaan karir melalui bimbingn karir dengan penggunaan Media Sosial". Jurnal PSKOPEDAGOGIA. Volume 3. Nomor 2. Hal. 58-64. (diakses 2014). Universitas Ahmad Dahlan.

Badan Pusat Statistik. 2018. "Keadaan Ketanagaankerjaan Provinsi Jawa Tengah Agustus 2018" Nomor 79/11/33/Th.XII. BPS Jawa Tengah. (diakses 05 November 2018).

Buzan, Tony. 2006. Buku Pinter Mind Map. Jakarta : PT Gramedia Pustaka Utama.

Inriana, irene. 2015. https://www.cnnindonesia.com/ekonomi/20151127113026-78-94450/pemerintahdiminta-waspadai-pengangguran-bertambah-akibat-mea? .Pemerintah diminta wapadai pengangguran bertamabh akibat MEA.Jakarta: CNN Indonesia.

Kaswan. 2014. Career Development (Pengembangan Karir untuk Mencapai Kesuksesan dan Kepuasan). Bandung: Alfabeta.

Meldona dan Siswanto. 2012. Perencanaan Tenaga Kerja. Malang: UIN MALIKI PRESS

Mahdalena Leksana, Dinar.dkk. 2013. Pengembangan Modul Bimbingan karir Berbasis Multimedia Interaktif untuk Meningkatkan Kematangan Karir Siswa. Jurnal Bimbingan dan Konseling Volume 2. Nomor 1. Hal 1-9. UNNES.(diakses Juni 2013).

Romlah, Tatiek. 2001. Teori dan Praktek Bimbingan Konseling. Malang : Universitas Negeri Malang.

Sugiyono. 2014. “Metode Penelitian Kuantitatif, Kualitatif dan R\&D”. Bandung: ALFABETA.

Yusuf, Syamsu \& Nurihsin Juntika, Achmad. 2011. Teori Kepribadian. Bandung: PT Rosdakarya. 